\title{
KEPUTUSAN PEMBELIAN PAKAIAN BATIK DITINJAU DARI KUALITAS PRODUK, PRODUCT ASSORTMENT, DAN STORE ATSMOSPHERE (Studi Pada Toko Batik Danar Hadi Surakarta)
}

\author{
Dhimas Wisnuaji Ikhsan, Bambang Mursito, Solichul Hadi \\ Fakultas Ekonomi Manajemen Universitas Islam Batik Surakarta \\ E-mail: wisnudhimas20@gmail.com
}

\begin{abstract}
This research aims to study and explain the simultaneous and partial Product Quality, Various Products and Atsmosphere Stores on the Purchase Decision of Batik Clothing at the Batik Danar Hadi Store in Surakarta. This research method uses descriptive quantitative research design. The population is all batik consumers at the Surakarta Danar Hadi Batik Shop, which gets 100 consumers. The number of samples is all consumers of 100 respondents. Collecting data using a questionnaire. Data analysis techniques used statistical analysis are the coefficient of determination test, multiple linear regression test, $F$ test, and t test. The results showed the product test, product quality, and store atmosphere simultaneously and significantly towards purchasing decisions at the Batik Danar Hadi Store in Surakarta. The results showed a positive and significant product quality on the buyer's decision at the Batik Danar Hadi Store in Surakarta. Product atsmosphere have a positive and significant influence on buyer's decision at the Batik Danar Hadi Store in Surakarta. Store atmosphere has a positive and significant influence on buyer's decision at the Batik Danar Hadi Store in Surakarta.
\end{abstract}

Keywords: Purchasing Decisions, Variety of Products, Product Assortment and Store Atmosphere

\section{PENDAHULUAN}

Persaingan di dunia bisnis pakaian telah terjadi peningkatan di berbagai Negara. Dengan bertambahnya bisnis pakaian yang menyebabkan datangnya pesaing baru yang bergabung kedalam lingkungan pasar sehingga pedagang yang terlebih dahulu menempatkan produk atau merek pakaian fashion nya harus mampu bersaing untuk mempertahankan kesan baik dan konsumen dapat membeli produk yang sudah ada.

Menurut Tobing dan Sihombing (2016) untuk meminimalkan ketidakpuasan konsumen, perusahaan harus memiliki strategi pasar berdampak pada keputusan konsumen dalam memilih produk lalu konsumen menjadi puas dan perusahaan harus melakukan penilaian suatu produk sebelum memasarkan produk. Beberapa faktor dapat mempengaruhi keputusan pembelian, yaitu tidak dipungkiri jika kualitas produk merupakan faktor penting untuk memberi pengaruh keputusan pembelian konsumen.

Menurut Santoso dan Harmoni (2016) Kualitas produk yang memiliki karakteristik bagus yang beda dan lebih unggul dari produk perusahaan kompetitor, dapat mendatangkan daya tarik dan minat pembeli dalam membeli produk. Hal tersebut dilakukan perusahaan agar menjaga pangsa pasarnya atau untuk memperlebar bagian pasar untuk menghasilkan hasil yang lebih.

Menurut Tobing dan Sihombing (2016) Keragaman produk dapat mempengaruhi terhadap keputusan pembelian konsumen, dimana sebagian besar konsumen lebih memilih toko yang mempunyai beberapa variasi produk, karena produk merupakan tanggapan dari konsumen yang dijelaskan melalui hasil produksinya. 
Menurut Girsang dan Widodo (2013) toko yang memiliki suasana yang bagus dan nyaman dapat memberikan kesan positif pada toko dan toko tersebut menjadi pilihan terbaik bagi konsumen dalam membeli sebuah produk.

\section{TINJAUAN PUSTAKA}

\section{Keputusan pembelian}

Menurut Kotler dan Amstrong (2014) mengungkapan keputusan pembelian yaitu langkah keputusan yang mana konsumen secara nyata melaksanakan pembelian suatu produk.

\section{Kualitas Produk}

Kualitas produk yaitu kemahiran perusahaan memberi identitas yang dapat menarik hati konsumen pada setiap produknya. Mowen (2012: 61), kualitas produk adalah proses penilaian secara menyeluruh pada konsumen untuk memperbaiki kinerja sebuah produk.

\section{Product Assortment}

Keragaman produk / product assortment merupakan beragam produk memiliki arti kelengkapan produk dari ukuran, merk dan kualitas produk serta kesiapan produk ketika berada dalam toko. Keanekaragaman produk menurut Vinci (2010: 84) adalah sebuah proses merencanakan dan pengelolaan keanekaragaman produk dalam suatu kelompok. Unsur kunci dalam persaingan bisnis yaitu keragaman produk.

\section{Store Atsmosphere}

Store atmosphere (suasana toko) yaitu suatu keunikan secara fisik yang penting untuk setiap usaha, memiliki peran sebagai menciptakan atmosfer yang nyaman dalam membuat pelanggan mau lama berada di toko. Penciptaan merk pada suatu toko tergantung kepada penyusaian kombinasi fisik yang bertujuan pada keahlian untuk menumbuhkan unsur keindahan dari kawasan toko sehingga mampu menggugah daya tarik bagi pelanggan (Bary, 2010).

\section{METODE PENELITIAN}

\section{Jenis Penelitian}

Riset yang dilakukan menggunakan metode kuantitatif dan mengumpulkan data dengan cara menyebar lembar pertanyaan.

\section{Waktu dan Tempat Penelitian}

Riset dilaksanakan di Jl. Dr. Rajiman No.164, Kemlayan, Kec. Serengan, Kota Surakarta, Jawa Tengah 57149. Waktu yang diperlukan penelitian ini dari bulan Agustus 2019 sampai Januari 2020. Dikerjakan mulai dari judul penelitian hingga penulisan hasil observasi.

\section{Populasi dan Sampel}

Dalam riset ini menggunakan populasi yaitu pembeli di Toko Batik Danar Hadi. Jumlah sampel pada riset ini yaitu 100 responden.

\section{Jenis dan Sumber Data}

Dalam riset ini menggunakan sumber data primer, sekunder dan penyebaran kuesioner kepada pembeli dari Toko Batik Danar Hadi tentang kualitas produk, product assortment, dan store atsmosphere. 


\section{HASIL DAN PEMBAHASAN}

1) Koefisien Determinasi

\begin{tabular}{|l|r|r|r|r|}
\hline $\begin{array}{l}\text { Mode } \\
1\end{array}$ & R & R Square & $\begin{array}{c}\text { Adjusted R } \\
\text { Square }\end{array}$ & $\begin{array}{c}\text { Std. Error of } \\
\text { the Estimate }\end{array}$ \\
\hline 1 & $.747^{\mathrm{a}}$ & .559 & .545 & 1.44586 \\
\hline
\end{tabular}

Dari hasil perhitungan didapat nilai adjusted $\mathrm{R}$ Square 0,545 atau 54,5\%. Artinya menunjukan 54,5\% dari keputusan pembelian bisa dijelaskan oleh variable independen (bebas) kualitas produk, product assortment, dan store atsmosphere. Selain itu 45,5\% variabel lainnya tidak dijelaskan di penelitian sekarang.

2) Analisis Regresi Linier Berganda

Regresi linier berganda dipakai agar dapat mengetahui seberapa jauh pengaruh variabel independen (kualitas produk, product assortment, dan store atmosphere) kepada variabel dependen (keputusan pembelian) di Toko Batik Danar Hadi.

\begin{tabular}{|c|c|c|c|c|}
\hline \multirow{2}{*}{\multicolumn{2}{|c|}{ Model }} & \multicolumn{2}{|c|}{$\begin{array}{l}\text { Unstandardized } \\
\text { Coefficients }\end{array}$} & \multirow{2}{*}{$\begin{array}{c}\begin{array}{c}\text { Standardized } \\
\text { Coefficients }\end{array} \\
\text { Beta }\end{array}$} \\
\hline & & B & Std. Error & \\
\hline \multirow{4}{*}{1} & $\begin{array}{l}\text { (Constant } \\
\text { ) }\end{array}$ & 1.218 & 1.886 & \\
\hline & TKPRO & .331 & .076 & .325 \\
\hline & TKER & .520 & .100 & .409 \\
\hline & TST & .215 & .068 & .237 \\
\hline
\end{tabular}

Diketahui uji regresi yang telah dilakukan, hasilnya yaitu $\mathrm{Y}=1,218+0,331 \mathrm{X}_{1}+0,520 \mathrm{X}_{2}-0,215 \mathrm{X}_{3}+\mathrm{e}$

Dari pernyataan di atas dapat diterangkan bahwa:

a. Nilai konstan (Y) sebesar 1,218 mempunyai arti apabila variabel bebas yaitu kualitas produk (X1), product assortment (keragaman produk) (X2), dan store atsmosphere (suasana toko) (X3) nilainya 0 , berarti keputusan pembelian mengalami peningkatan $(1,218)$.

b. Koefisien regresi variabel kualitas produk (b1) dalam perhitungan regresi linier sederhana nilai coefficients $(\mathrm{b})=0,331$. Berarti bahwa setiap ada peningkatan kualitas produk, dengan perkiraan variabel lain tidak berubah berarti keputusan pembelian mengalami peningkatan $(0,331)$.

c. Koefisien regresi variabel product assortment (b2) dalam perhitungan regresi linier sederhana nilai coefficients $(\mathrm{b})=0,520$. Berarti bahwa setiap ada peningkatan product assortment, dengan perkiraan variabel lain tidak berubah berarti keputusan pembelian mengalami peningkatan $(0,520)$.

d. Koefisien regresi variabel store atsmosphere (b3) dalam perhitungan regresi linier sederhana nilai coefficients $(\mathrm{b})=0,215$. Berarti bahwa setiap ada peningkatan store atsmosphere, dengan perkiraan variabel lain tidak berubah berarti keputusan pembelian mengalami peningkatan $(0,215)$. 
3) Uji Asumsi Klasik

a. Uji Normalitas

\begin{tabular}{|ll|r|}
\hline & & $\begin{array}{r}\text { Unstandardiz } \\
\text { ed Residual }\end{array}$ \\
\hline $\mathrm{N}$ & Mean & 100 \\
Normal Parameters ${ }^{\mathrm{a}, \mathrm{b}}$ & Std. & .0000000 \\
& Deviation & 1.42378357 \\
Most Extreme & Absolute & .106 \\
Differences & Positive & .106 \\
\multicolumn{2}{l|}{ Kolmogorov-Smirnov Z Z } & -.073 \\
Asymp. Sig. (2-tailed) & & 1.059 \\
\hline
\end{tabular}

Dari output one sampel test di atas menyatakan hasil perhitungan signifikansi 0,212>0,05. Artinya residualnya berdistribusi normal.

b. Uji Multikoleniaritas

\begin{tabular}{|ll|l|l|}
\hline \multicolumn{2}{|l|}{ Model } & \multicolumn{2}{|l|}{ Collinearity Statistics } \\
\cline { 3 - 4 } & & Tolerance & VIF \\
\hline \multirow{4}{*}{1} & (Constant) & & \\
& TKPRO & .824 & 1.213 \\
& TKER & .741 & 1.349 \\
& TST & .814 & 1.229 \\
\hline
\end{tabular}

Hasil uji multikoleniaritas pada tabel tersebut mengungkapkan bahwa variabel bebas (kualitas produk, product assortment, dan store atsmosphere) diperoleh nilai tolerance > 0,1 dan nilai VIF $<10$, yang berarti tidak terjadi gejala multikoleniaritas.

c. Uji Heteroskedastisitas

\begin{tabular}{|c|c|c|c|c|c|c|}
\hline \multirow{2}{*}{\multicolumn{2}{|c|}{ Model }} & \multicolumn{2}{|c|}{$\begin{array}{l}\text { Unstandardized } \\
\text { Coefficients }\end{array}$} & \multirow{2}{*}{$\begin{array}{c}\text { Standardize } \\
\mathrm{d} \\
\text { Coefficient } \\
\mathrm{s}\end{array}$} & \multirow[t]{2}{*}{$\mathrm{t}$} & \multirow[t]{2}{*}{ Sig. } \\
\hline & & B & Std. Error & & & \\
\hline \multirow{4}{*}{1} & $\begin{array}{l}\text { (Constan } \\
\text { t) }\end{array}$ & .831 & 1.228 & & .677 & .500 \\
\hline & TKPRO & .043 & .049 & .096 & .864 & .390 \\
\hline & TKER & .028 & .065 & .050 & .427 & .670 \\
\hline & TST & -.059 & .044 & -.150 & -1.342 & .183 \\
\hline
\end{tabular}

Pada output di atas menunjukan nilai signifikan dari tiga variabel independen (bebas) lebih dari 0,05. Berarti memiliki kesimpulan bahwa tidak mengalami heteroskedastisitas. 
4) Uji Hipotesis

a. Uji t

\begin{tabular}{|c|c|c|c|c|c|c|}
\hline \multirow{2}{*}{\multicolumn{2}{|c|}{ Model }} & \multicolumn{2}{|c|}{$\begin{array}{c}\text { Unstandardized } \\
\text { Coefficients }\end{array}$} & \multirow{2}{*}{$\begin{array}{c}\begin{array}{c}\text { Standardize } \\
\mathrm{d} \\
\text { Coefficients }\end{array} \\
\text { Beta }\end{array}$} & \multirow[t]{2}{*}{$\mathrm{t}$} & \multirow[t]{2}{*}{ Sig. } \\
\hline & & B & Std. Error & & & \\
\hline \multirow{4}{*}{1} & $\begin{array}{l}\text { (Constan } \\
\text { t) }\end{array}$ & 1.218 & 1.886 & & .646 & .520 \\
\hline & TKPRO & .331 & .076 & .325 & 4.356 & .000 \\
\hline & TKER & .520 & .100 & .409 & 5.187 & .000 \\
\hline & TST & .215 & .068 & .237 & 3.160 & .002 \\
\hline
\end{tabular}

1) Dari perhitungan diperoleh $t_{\text {hitung }}>t_{\text {tabel }}(4,356>1,984)$ dengan nilai signifikansi 0,000 $<0,05$ yang artinya Ho ditolak, maka hasil ini mengungkapkan kualitas produk mempunyai pengaruh positif dan signifikan kepada keputusan pembelian.

2) Dari perhitungan diperoleh $t_{\text {hitung }}>\mathrm{t}_{\text {tabel }}(5,187>1,984)$ dengan nilai signifikansi 0,000 $<0,05$ yang artinya Ho ditolak, maka hasil ini menunjukan bahwa product assortment memilki pengaruh positif dan signifikan kepada keputusan pembelian.

3) Dalam perhitungan diperoleh $t_{\text {hitung }}>t_{\text {tabel }}(3,160>1,984)$ dengan nilai signifikansi $0,002<0,05$ berarti Ho ditolak, maka hasil ini menunjukan store atsmosphere berpengaruh positif dan signifikan kepada keputusan pembelian.

b. Uji F

Berguna untuk mengetahui signifikansi antara variabel kualitas produk, product assortment, dan store atsmosphere adanya pengaruh secara simultan kepada keputusan pembelian.

\begin{tabular}{|c|c|c|c|c|c|c|}
\hline \multicolumn{2}{|c|}{ Model } & $\begin{array}{l}\text { Sum of } \\
\text { Squares }\end{array}$ & df & $\begin{array}{l}\text { Mean } \\
\text { Square }\end{array}$ & $\mathrm{F}$ & Sig. \\
\hline \multirow{3}{*}{1} & $\begin{array}{l}\text { Regressio } \\
n\end{array}$ & 254.061 & 3 & 84.687 & 40.510 & $.000^{\mathrm{b}}$ \\
\hline & Residual & 200.689 & 96 & 2.091 & & \\
\hline & Total & 454.750 & 99 & & & \\
\hline
\end{tabular}

Dari analisis data di atas, dapat diketahui bahwa nilai $\mathrm{F}_{\text {hitung sebesar 40,510 dikarenakan }}$ $F_{\text {hitung }}>F_{\text {tabel }}(40,510>2,70)$ dan signifikansi $0,000<0,05$ maka Ho ditolak. Dapat disimpulkan $\mathrm{H} 1$ diterima, berarti berpengaruh signifikan antara kualitas produk, product assortment, dan store atsmosphere secara simultan kepada keputusan pembelian.

\section{PEMBAHASAN}

1) Pengaruh Kualitas Produk, Product Assortment, dan Store Atsmosphere kepada Keputusan Pembelian pakaian batik di Toko Batik Danar Hadi Surakarta.

a. Berdasarkan hasil uji F maka diketahui Fhitung > Ftabel $(40,510>2,70)$ dan signifikansi $0,000<0,05$. Artinya kualitas produk, product assortment, dan store 
atsmosphere secara bersama-sama berpengaruh signifikan kepada keputusan pembelian pakaian batik dalam Toko Batik Danar Hadi.

2) Pengaruh kualitas produk kepada keputusan pembelian pada Toko Batik Danar Hadi Surakarta.

a. Hasil perhitungan didapatkan $t_{\text {hitung }}>t_{\text {tabel }}(4,356>1,984)$ dengan nilai signifikansi $0,000<0,05$ yang artinya Ho ditolak, berarti hasil menunjukan kualitas produk berpengaruh positif dan signifikan kepada keputusan pembelian pakaian batik dalam Toko Batik Danar Hadi Surakarta.

3) Pengaruh keragaman produk (product assortment) kepada keputusan pembelian di Toko Batik Danar Hadi Surakarta.

a. Hasil perhitungan didapatkan $t_{\text {hitung }}>t_{\text {tabel }}(5,187>1,984)$ memiliki nilai signifikan $0,000<0,05$ yang artinya Ho ditolak, berarti menampilkan keragaman produk mempunyai pengaruh positif dan signifikan kepada keputusan pembelian pakaian batik di Toko Batik Danar Hadi Surakarta.

4) Pengaruh store atsmosphere (suasana toko) kepada keputusan pembelian pada Toko Batik Danar Hadi Surakarta.

a. Hasil perhitungan didapatkan thitung $>$ ttabel $(3,160>1,984)$ memiliki nilai signifikan $0,002<0,05$ yang artinya Ho ditolak, berarti store atsmosphere berpengaruh positif dan signifikan kepada keputusan pembelian pakaian batik di Toko Batik Danar Hadi Surakarta.

\section{KESIMPULAN}

Kesimpulan dari observasi diperoleh:

1) Variabel Kualitas produk, Product assortment (keragaman produk), dan Store atsmosphere secara simultan memilki pengaruh signifikan kepada keputusan pembelian pakaian batik dalam Toko Batik Danar Hadi Surakarta.

2) Variabel kualitas produk (X1) secara parsial memiliki pengaruh positif dan signifikan kepada keputusan pembelian pakaian batik dalam Toko Batik Danar Hadi.

3) Variabel keanekaragaman produk (product assortment) berpengaruh positif dan signifikan secara parsial kepada keputusan pembelian pakaian batik di Toko Batik Danar Hadi.

4) Variabel store atsmosphere (suasana toko) secara parsial berpengaruh positif dan signifikan kepada keputusan pembelian pakaian batik dalam Toko Batik Danar Hadi.

\section{Saran}

1) Dari hasil riset, di harapkan pihak Batik Danar Hadi Surakarta untuk secara berkala melakukan kegiatan pengawasan keragaman produk dan selalu berinovasi dalam penataan lay out produk, karena hal tersebut berpengaruh yang tertinggi terhadap menarik keputusan pembelian produk.

2) Berdasarkan hasil penelitian, pihak Batik Danar Hadi Surakarta perlu lebih memfokuskan suasana toko yang menarik dalam menciptakan suasana yang lebih nyaman, sehingga membuat daya tarik konsumen untuk melakukan keputusan pembelian Batik Danar Hadi Surakarta.

3) Diharapkan riset selanjutnya untuk lebih mengembangkan riset ini dengan memakai variabel bebas lainnya selain kualitas produk, product assortment (keragaman produk), dan store atsmosphere (suasana toko) yang dapat mempengaruhi keputusan pembelian. 


\section{DAFTAR PUSTAKA}

Tobing Morina Fitri, Sihombing Dionisius.(2016). Pengaruh Lokasi, Keragaman Produk Dan Harga Terhadap Keputusan Pembelian (Studi Pada Carrefour Citra Garden Medan). Jurnal PLANS. Volume 11 no. 2, September 2016.

Santoso Adi, Harmoni. (2016). Pengaruh Kualitas Produk dan Ekuitas Merek Terhadap Keputusan Pembelian. Jurnal Ekuilibrium, Volume 11, Nomor 1, Maret 2016.

Putri Julianti Girsang, Arry Widodo. (2013). Pengaruh store atmosphere dan product assortment terhadap minat beli pada the secret factory outlet Bandung.

Kotler, Philip dan Amstrong, Gary, (2014), Principles of Marketing, 12th Edition, Jilid 1 Terjemahan Bob Sabran Jakarta: Erlangga.

Mowen, John C dan Minor, Micheal. (2012). Perilaku Konsumen dialih bahasakan oleh Dwi Kartika Yahya. Jakarta: Erlangga.

Berman, Baryy and Joel R. Evans. (2012). Retail Management: A Strategic Approach. 